\title{
International Classification of Diseases, Eleventh Revision, Clinical Modification
}

National Cancer Institute

\section{Source}

National Cancer Institute. International Classification of Diseases, Eleventh Revision,

Clinical Modification. NCI Thesaurus. Code C154413.

An extension of the ICD-11 created by the U.S. National Center for Health Statistics so that the system could be used to capture more morbidity data. 